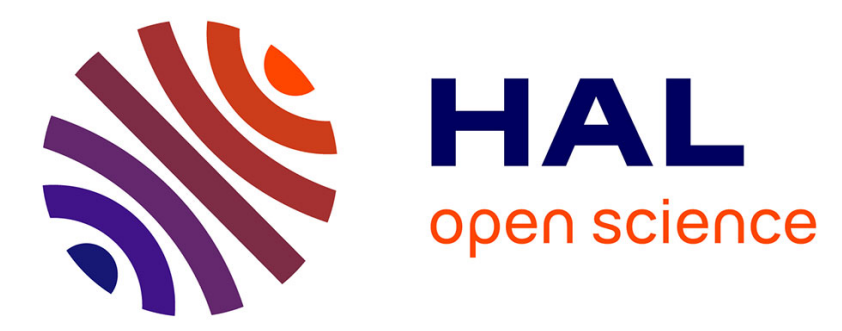

\title{
Jet-cooled rovibrational spectroscopy of methoxyphenols using two complementary FTIR and QCL based spectrometers
}

P. Asselin, J Bruckhuisen, A Roucou, Manuel Goubet, M.-A. Martin-Drumel, A Jabri, Y Belkhodja, P Soulard, Robert Georges, A. Cuisset

\section{To cite this version:}

P. Asselin, J Bruckhuisen, A Roucou, Manuel Goubet, M.-A. Martin-Drumel, et al.. Jet-cooled rovibrational spectroscopy of methoxyphenols using two complementary FTIR and QCL based spectrometers. Journal of Chemical Physics, 2019, 151 (19), pp.194302. 10.1063/1.5128196 . hal-02356097

\section{HAL Id: hal-02356097 https://hal.science/hal-02356097}

Submitted on 8 Nov 2019

HAL is a multi-disciplinary open access archive for the deposit and dissemination of scientific research documents, whether they are published or not. The documents may come from teaching and research institutions in France or abroad, or from public or private research centers.
L'archive ouverte pluridisciplinaire HAL, est destinée au dépôt et à la diffusion de documents scientifiques de niveau recherche, publiés ou non, émanant des établissements d'enseignement et de recherche français ou étrangers, des laboratoires publics ou privés. 


\title{
Jet-cooled rovibrational spectroscopy of methoxyphenols using two complementary FTIR and QCL based spectrometers
}

\author{
P. Asselin ${ }^{1}$, J. Bruckhuisen ${ }^{1}$, A. Roucou2,*, M. Goubet³ ${ }^{3}$, M.-A. Martin-Drumel ${ }^{4}$, A. \\ JABRI $^{1,2, * *}$, Y. Belkhodja ${ }^{1}$, P. SOULARD ${ }^{1}$, R. GeORGES ${ }^{5}$, AND A. CuISSET ${ }^{2}$ \\ ${ }^{1}$ Laboratoire MONARIS, UMR-CNRS 8233, Sciences Sorbonne université, Paris, Université Pierre et Marie Curie, 75252, Paris, France. \\ ${ }^{2}$ Laboratoire de Physico-Chimie de l'Atmosphère, EA-4493, Université du Littoral Côte d'Opale, 59140 Dunkerque, France. \\ *Present address: Faculté des sciences, Institute of Condensed Matter and Nanosciences, Louvain la Neuve, Belgium \\ ${ }^{3}$ Université de Lille, CNRS, UMR8523 PhLAM Physique des Lasers Atomes et Molécules, F-59000 Lille, France \\ ${ }^{4}$ Institut des Sciences Moléculaires d'Orsay (ISMO), CNRS, Univ. Paris-Sud, Université Paris-Saclay, F-91405 Orsay, France \\ ** Present address: Grupo de Espectroscopia Molecular, Universidad de Valladolid, Spain \\ ${ }^{5}$ Université de Rennes, CNRS, IPR (Institut de Physique de Rennes) - UMR 6251, F-35000 Rennes, France.
}

Contact corresponding author(s): arnaud.cuisset@univ-littoral.fr

Final accepted article compiled on November 8, 2019

Published in: The Journal of Chemical Physics tbd, tbd (2019) https://doi.org/10.1063/1.5128196

\begin{abstract}
Methoxyphenols (MP) are a significant component of biomass burning emissions which mainly exists in our atmosphere in the gas phase where they contribute to the formation of secondary organic aerosols (SOA). Rovibrational spectroscopy is a promising tool to monitor atmospheric MPs and infer their role in SOAs formation. In this study, we bring a new perspective on the rovibrational analysis of MP isomers by taking advantage of two complementary devices combining jet-cooled environments and absorption spectroscopy: the Jet-AILES and the SPIRALES setups. Based on Q-branches frequency positions measured in the Jet-AILES FTIR spectra and guided by quantum chemistry calculations, we propose an extended vibrational and conformational analysis of the different MP isomers in their fingerprint region. Some modes such as far-IR out-of-plane -OH bending or mid-IR in-plane - $\mathrm{CH}$ bending allow to assign individually all the stable conformers. Finally, using the SPIRALES setup with three different EC-QCL sources centered on the $930-990 \mathrm{~cm}^{-1}$ and the $1580-1690 \mathrm{~cm}^{-1}$ ranges, it was possible to proceed to the rovibrational analysis of the $v_{18}$ ring in-plane bending mode of the MP meta isomer providing a set of reliable excited state parameters which confirms the correct assignment of two conformers. Interestingly, the observation of broad Q-branches without visible $\mathrm{P}$ - and $\mathrm{R}$ - branches in the region of the $\mathrm{C}-\mathrm{C}$ ring stretching bands was interpreted as being probably due to a vibrational perturbation. These results highlight the complementarity of broadband FTIR and narrowband laser spectroscopic techniques to reveal the vibrational conformational signatures of atmospheric compounds over a large infrared spectral range.
\end{abstract}

\section{INTRODUCTION}

Methoxyphenols $\left(\mathrm{H}_{3} \mathrm{CO}-\mathrm{C}_{6} \mathrm{H}_{4}-\mathrm{OH}, \mathrm{MP}\right)$ are aromatic oxygenated compounds present in our atmosphere in their three isomeric forms: 2MP (also called guaiacol), 3MP, and 4MP (also called mequinol), which designate the ortho, meta and para isomers. MPs have a high emission rate from biomass burning and mainly exist in the gas phase. [1,2] MPs contribute to the secondary organic aerosols (SOA) formation in the at- mosphere via $\mathrm{OH}$-oxydation processes [3, 4]. The ability to monitor in the atmosphere MPs as SOA precursors is required to fully understand the SOA atmospheric chemical cycle and thus infer their impact on the climate. Compared to lighter volatile organic compounds, it is not currently possible to detect and quantify MPs in the atmosphere by measuring their high resolution rovibrational signatures using on-board instruments such as IASI/MetOp [5] or ACE-FTS[6] sounders. 
A key parameter for atmospheric monitoring of molecules is the rovibrational cross-sections that can be determined from rovibrational measurements in the laboratory. For MPs, only vibrational cross-sections have been determined so far. Their measurements were performed using synchrotron-based roomtemperature Fourier-transform infrared (FTIR) absorption spectroscopy on the AILES beamline at the synchrotron SOLEIL [7]. These cross-sections were determined at low resolution $\left(0.5 \mathrm{~cm}^{-1}\right)$ by integrating the rovibrational patterns but it was never possible to fully resolve the rotational structure even at the maximal resolution of the interferometer $\left(0.001 \mathrm{~cm}^{-1}\right)$ due to the huge density of states populated at ambient temperature. Furthermore, the different conformers of each isomer could not be distinguished. Only millimeter-wave ( $\mathrm{mmw}$ ) spectroscopy allowed to fully resolve Doppler limited rotational structure at $300 \mathrm{~K}$. as demonstrated recently with a full conformational analysis in the ground and in the lowest energy vibrational states of the three MP isomers using mmw absorption and emission spectroscopies [8,9]. These studies emphasized the congestion of lines in MPs spectra due to rather small rotational constants and the presence of several conformers and pure rotational transitions within the low-lying vibrational excited states. To the best of our knowledge, the only high resolution rovibrational data on MPs have been obtained at low temperature by the group of T. Zwier [10] and the group of M. Schmitt [11, 12] using respectively free-jet fluorescence dip infrared spectroscopy and molecular beam rotationally resolved electronic spectroscopy. While the first group focused on the anharmonic coupling in the C-H stretch region, the second group provides MP conformational analyses in the electronically excited states.

In the present study, we investigate MPs rovibrational spectra at low temperature by taking advantage of two complementary supersonic jet devices associated to two different infrared spectroscopic methods: (i) the Jet-AILES apparatus, coupled to the AILES beamline at synchrotron SOLEIL, which was used for low resolution broadband FTIR scans of the three MP isomers in the fingerprint region (900-1700 $\left.\mathrm{cm}^{-1}\right)$; and (ii) the SPIRALES setup, with mid-IR external cavity quantum cascade laser (ECQCL) sources coupled to a pulsed molecular jet. The latter setup allowed to fully resolve the $v_{18}$ IR band of $3 \mathrm{MP}$ centered at $950 \mathrm{~cm}^{-1}$, to fit the rotational constants in this in-plane ring bending mode and to assess the conformational landscape previously determined.[8] Moreover, using a second QCL source centered around $1610 \mathrm{~cm}^{-1}$, strong rovibrational broadenings have been observed for the $v_{36}$ and $v_{37}$ modes, highlighting a likely vibrational perturbation. In the following, a brief description of experimental and theoretical methods is presented in a first section. Experimental results will be detailed and discussed in a second section: first, the vibrational/conformational assignment of the broadband Jet-AILES FTIR spectra; then, the high-resolution analyses of the $v_{18}, v_{36}$ and $v_{37}$ bands of $3 \mathrm{MP}$ measured by the SPIRALES setup.

\section{METHODS}

\section{A. Experimental measurements}

Commercially available MP isomers with stated purities higher than $98 \%$ were purchased from Acros Organics. Further purification was performed by continuous pumping over the samples for about $24 \mathrm{~h}$ in order to eliminate methanol traces. Due to the low volatility of MP compounds, liquid 2MP and 3MP (138 and $27 \mu$ bar of room temperature vapor pressure [13]) and solid 4MP (9 $\mu$ bar [13]) samples were heated in all experiments.

\section{A.1. Jet-AILES setup}

Jet-cooled spectra were recorded using the Jet-AILES apparatus, a continuous molecular jet experiment coupled to the highresolution Bruker IFS 125 FTIR spectrometer installed on the AILES beamline of the SOLEIL synchrotron facility. This setup was previously described in detail $[14,15]$ thus only relevant parameters to the present study are reported here. A slit nozzle of $60 \mathrm{~mm}$ length and $130 \mu \mathrm{m}$ width is used to expand the sample seeded in a buffer gas into an expansion chamber continuously evacuated by a set of roots pumps. The flow of liquid samples (2MP and 3MP) vapor through the nozzle is regulated using a Controlled Evaporation Mixer (CEM) supplied by regulated flows of argon or helium as buffer gas and liquid MP. 2MP and 3MP samples are respectively heated to $373 \mathrm{~K}$ and 413 $\mathrm{K}$. The injection line between the CEM and the slit is also heated at these temperatures to prevent condensation. For solid 4MP, an oven heated up to $438 \mathrm{~K}$ is used instead of the CEM. Such heating enabled to reach vapor pressure levels as high as about 10 mbar for each MP, a necessary condition to record their vibrational spectra with a sufficient signal-to-noise ratio (SNR). Spectra are recorded with flows of the buffer gas ranging from 5 to 30 standard $1 . \mathrm{min}^{-1}$ (slm). The reservoir and chamber pressures are typically maintained around $70 \mathrm{mbar}$ and $0.1 \mathrm{mbar}$, respectively, resulting in a rotational temperature of about $30 \mathrm{~K}$.

High-resolution $\left(0.001 \mathrm{~cm}^{-1}\right)$ tests were performed but the limited sensitivity of the continuous jet-FTIR setup (single pass through the expansion) prevented from a sufficient SNR to be achieved. Consequently, for each sample and each expansion condition, a jet-cooled FT spectrum consisting of 200 co-added interferograms was recorded at 0.1 $\mathrm{cm}^{-1}$ resolution. The most suitable combination of infrared source/beamsplitter/detector combination, namely Globar/Mylar/Si bolometer and Globar/KBr-Ge/HgCdTe was used for the far-IR (150-650 $\left.\mathrm{cm}^{-1}\right)$ and the mid-IR (1000-1700 $\mathrm{cm}^{-1}$ ) regions, respectively.

\section{A.2. SPIRALES setup}

The SPIRALES spectrometer, which couples an EC-QCL and a pulsed supersonic jet, proved to be an extremely sensitive probe of low temperature rovibrational spectra of heavy polyatomic molecules and molecular complexes[16, 17]. The main characteristics of the instrument are summarized in the following paragraph. The absorption light source is a continuous-wave room-temperature mode-hop-free EC-QCL (Daylight Solutions) of $10 \mathrm{MHz}$ spectral width. In the present study, three EC-QCLs were used which cover the following spectral ranges: 930-990 $\mathrm{cm}^{-1}$ (Model $21106 \mathrm{MHF}$ ), $1580-1640 \mathrm{~cm}^{-1}$ (Model 41062- 
MHF) and 1620-1690 $\mathrm{cm}^{-1}$ (Model 21060-MHF). About $8 \%$ of the total light power was sent through two laser channels for relative and absolute frequency calibrations. Absolute frequency calibration was achieved by comparing the frequency deviation of lines of $\mathrm{C}_{2} \mathrm{H}_{4}$ (in the the 930-990 $\mathrm{cm}^{-1}$ range) and $\mathrm{NH}_{3}$ and $\mathrm{H}_{2} \mathrm{O}$ (in the $1580-1690 \mathrm{~cm}^{-1}$ range) between experimental and well-known standard (from the HITRAN2012 database [18]).This procedure allows to correct the free spectral range value of the reference fixed at the beginning of each experiment. The remaining light is sent through a multi pass astigmatic cavity accorded to a 182-pass pattern which crosses almost perpendicularly the jet expansion. Jet-cooled MP molecules were probed over axial distances between 5 and $15 \mathrm{~mm}$ from the nozzle exit due to the relatively large zone covered by the optical cavity. The molecular jet was produced using a pulsed $1 \mathrm{~mm}$ diameter pin hole nozzle from General Valve Series 9 model, controlled by a valve driver (Iota One, Parker Hannifin). MP compounds were seeded in the supersonic jet using a brass block fitted to a Dural reservoir filled with $0.5 \mathrm{~g}$ of sample. The reservoir located close upstream to the expansion zone was heated up to $420 \mathrm{~K}$ to increase the sample vapor pressure which was then carried away by argon. Typical conditions used in this work were about $1 \%$ of MP in $0.15 \mathrm{MPa}$ of Ar. The seeded mixture was then cooled down by converting the circular flow of the standard valve configuration into a planar expansion using a multichannel interface ended with two modified industrial blades, forming a $30 \mathrm{~mm}$ length and $150 \mu \mathrm{m}$ width slit aperture. Guided by calculated anharmonic frequencies and intensities of MP compounds in the fingerprint region, band intensities of $v_{18}, v_{36}$ and $v_{37}$ transitions of $4 \mathrm{MP}$ are expected to be weak. As a consequence, only $3 \mathrm{MP}$ and $2 \mathrm{MP}$ were investigated in the available spectral range of our EC-QCLs. Spectra were recorded using a rapid scan scheme similar to previous designs developed for high resolution molecular spectroscopy [19, 20]. Spectra are recorded by driving the piezo-electic transducer of the EC-QCL diffraction grating with a $100 \mathrm{~Hz}$ sine wave. This allows the QCL frequency to be scanned once per period over $0.8 \mathrm{~cm}^{-1}$ with a frequency sampling of about $3 \mathrm{MHz}$. A baseline-free transmittance through the multipass cavity is obtained by taking the ratio of signals recorded in the presence and absence of the jet. The accuracy of the frequency calibration is around $0.0015 \mathrm{~cm}^{-1}$ slightly degraded by the Doppler broadening from non orthogonal laser and planar jet crossings in the multi pass optical cavity.

\section{B. Quantum chemical calculations}

High level of theory quantum chemical calculations on MPs were performed using the Gaussian 16 package [21] and have already been described elsewhere. [8,9] Briefly, optimized equilibrium structures and vibrational frequencies were calculated using the B3LYP functional and Dunning correlation consistent basis set cc-pVTZ [22]. This functional/basis set combination has proven to be extremely reliable in the computational study on the molecular conformations of phenolic compounds [23]. Here, the optimization process used the tight SCF convergence criterion and ultrafine grid to provide energies in the fundamental electronic state, rotational constants and dipole moments of the stable conformers as well as conformational barriers. Anharmonic frequencies, determined with the VPT2 method[24] as implemented in Gaussian 16, have been computed using the same level of theory.

\section{RESULTS AND DISCUSSION}

\section{A. Broadband low resolution Jet-AILES spectra}

\section{A.1. Determination of optimum flow conditions}

The 3MP isomer spectrum has been investigated under various experimental conditions to optimize the SNR of the recorded MPs vibrational spectra. Fig. 1 displays an example of $3 \mathrm{MP}$ jetcooled mid-IR spectra measured for three different mass flow rates of Ar buffer gas. Several Q-branches are distinguishable on all spectra, but these Q-branches became readily observed with a rather good SNR on the $5 \mathrm{slm}$ of Ar spectrum (see Fig.1a). When using Ar flow rates of 10 and 20 slm, additional bands, absent from the $5 \mathrm{slm}$ spectrum, can be observed (see e.g. the band around $1460 \mathrm{~cm}^{-1}$ on the inset of Fig. 1). These bands are most likely resulting from argon coating, i.e. the formation of 3MP-(Ar) ${ }_{n}$ complexes, $n \geq 1[25,26]$. Q-branches are clearly observed with a rather good SNR owing to an absence of MP$(\mathrm{Ar})_{n}$ hetero complexes at lower dilution of the MP/Ar mixture. Both to ensure a good rotational cooling and to prevent the formation of Ar complexes, flow of $5 \mathrm{slm}$ of Ar appears to be most suitable to investigate the remaining MP compounds.

Far-IR and mid-IR Jet-AILES spectra of 3MP have also been recorded with $\mathrm{He}$ as buffer gas in order to select the most adapted carrier gas. In similar experimental conditions, use of Ar gas resulted in higher SNR, thus this carrier was used in subsequent measurements.

\section{A.2. Rovibrational cooling}

In Fig. 2, 3MP spectra in jet-cooled conditions are compared with the room-temperature spectra obtained previously [7] to assess the rovibrational cooling in the supersonic expansion. While at first glance the overall contour of the vibrational bands appears mostly similar in both conditions, revealing the probing of thermalized gas within the boundary layer of the expansion, significant rovibrational cooling can be assessed from the presence of narrow Q-branches in the spectra. In the far-IR (see Fig. 2a), these branches are even the only significant contribution that can be distinguished. Moreover, the complex Q-branch structure observed in the room temperature spectrum is strongly reduced in jet-cooled conditions, corresponding to a strong decrease of hot bands intensities.

\section{A.3. Vibrational and conformational analysis}

Jet-AILES far-IR and mid-IR spectra of the three MP isomers are displayed in Fig. 3 and Fig. 4, respectively. The vibrational spectra in the mid-IR region are of better quality, in terms of SNR, than in the far-IR, as expected from the presence of more intense modes and a higher FT sensitivity (IR source, detector). An enlarged view of the strongest Q-branches associated with the out-of-plane $\mathrm{OH}$ bending modes is also presented in Fig. 3c.

As previously demonstrated by the room temperature spectra[7], the far-IR region exhibits very different rovibrational 


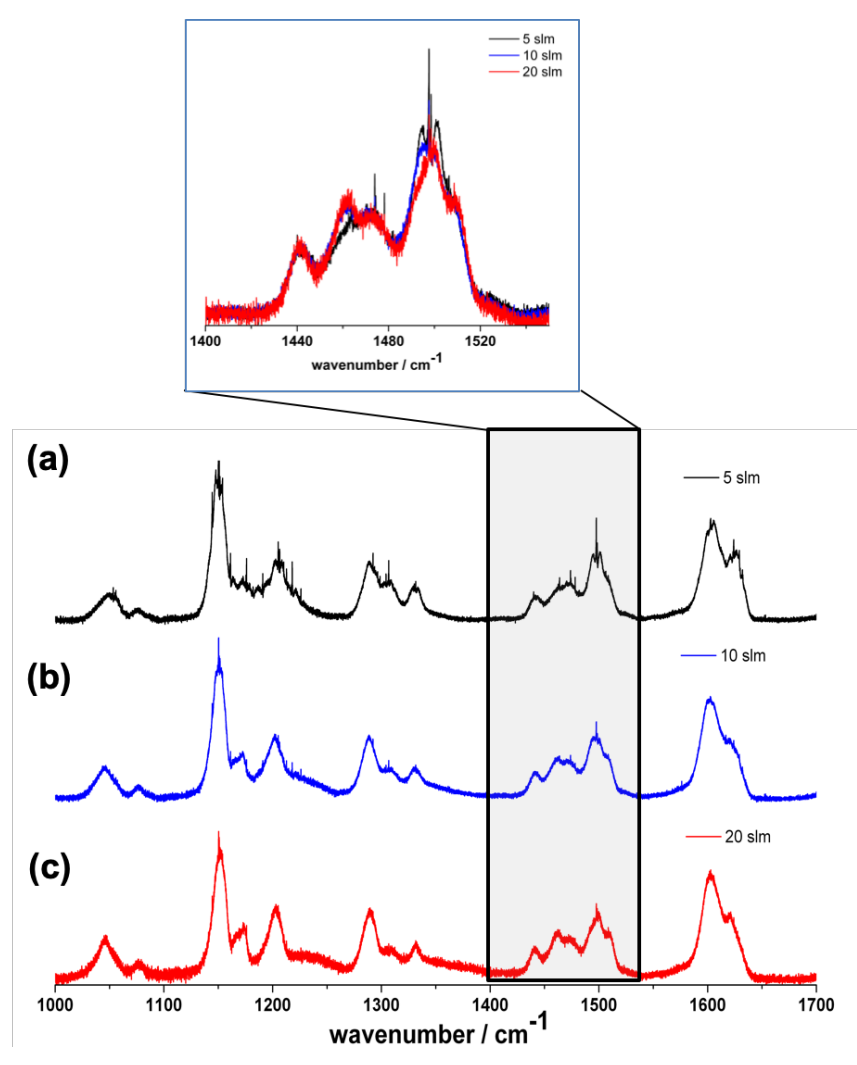

Fig. 1. Evolution of the 3MP Jet-AILES mid-IR spectra (1000$1700 \mathrm{~cm}^{-1}$ ) for three different flow rates of Ar: $5 \mathrm{slm}$ (in black, Fig. 1a), $10 \mathrm{slm}$ (in blue, Fig. 1b), and $20 \mathrm{slm}$ (in red, Fig. 1c); from top to bottom. Inset: Zoom onto the $1400-1550 \mathrm{~cm}^{-1}$ region revealing narrow $\mathrm{Q}$ branches at lower dilution and the possible formation of MP-(Ar) ${ }_{n}$ complexes (as evidenced by the apparition of a band around $1460 \mathrm{~cm}^{-1}$ ) at higher Ar flow rates.

signatures for 2MP, 3MP and 4MP with a strong dependence of the out-of-plane $\mathrm{OH}$ bending modes to the isomeric forms. In addition to the previous room-temperature investigation[7], jetcooled spectra enable both a determination of band centers at the instrumental accuracy (sharp Q-branches thanks to strongly reduced thermal shift/broadening), $0.1 \mathrm{~cm}^{-1}$ in the present study, and the investigation of the conformational landscape of MPs (discrimination of the contribution of each conformer according to jet conditions). The anharmonic predictions (B3LYP/ccpVTZ) facilitate the band assignment in the mid-IR region while the low-frequency modes in the far-IR region are essentially assigned on the basis of the harmonic predictions (see details hereafter). We base our conformational analysis on the relative frequency difference (using the calculated values) between each conformer of a given MP for a given vibrational mode. The analysis of the spectra of each MP isomer is detailed hereafter. Tables 1-3 report the conformer dependent band center assignments of the three MP compounds.

With only one stable conformer denoted 2MP-C1 stabilized by an intramolecular hydrogen bond [17], 2MP exhibits the most simple far-IR spectrum. In the far-IR, two main signals are observed at $429.9 \mathrm{~cm}^{-1}$ and $433.8 \mathrm{~cm}^{-1}$ corresponding to the Q-branches of the out-of-plane $\mathrm{OH}$ bending modes: in-phase $v_{7}$ and out-of-phase $v_{8}$, respectively (with respect to the out-ofplane $\mathrm{CH}$ ring deformations). In the mid-IR, 15 signals have been assigned at the instrumental accuracy thanks to the narrow Q-branches observed in jet-cooled conditions (see Table 1).

The 3MP isomer exhibits the richest conformational landscape with four stable conformers at room temperature, namely 3MP-C1 to 3MP-C4 (see Fig. 3a), as evidenced by previous rotationally resolved spectroscopic studies $[8,11]$. In the far-IR, the $v_{6}$ out-of-plane $\mathrm{OH}$ bending mode has a very strong band intensity ( $\mathrm{I}_{\text {harm }}>90 \mathrm{~km} / \mathrm{mol}$ ) compared to the other low-frequency vibrations $\left(\mathrm{I}_{\mathrm{harm}}<10 \mathrm{~km} / \mathrm{mol}\right.$ ) which are most probably below our detection limit. Therefore, the four signals observed at 318.9 $\mathrm{cm}^{-1}, 321.1 \mathrm{~cm}^{-1}, 311.9 \mathrm{~cm}^{-1}$ and $292.7 \mathrm{~cm}^{-1}$ (see Fig. 3c) can be assigned to the $\mathrm{C} 1, \mathrm{C} 2, \mathrm{C} 3$ and $\mathrm{C} 4$ conformers of $3 \mathrm{MP}$, respectively, according to the relative populations determined in the ground state (GS) [8] and to the calculated harmonic frequencies and intensities (see supplementary materials Tables S2-S5). Due to the nearly same harmonic intensities of four conformers in the case of the $v_{6}$ mode, relative observed intensities should mainly reflect the population distribution in the jet. Comparison with the relative population of 3-MP determined at room temperature in the GS [8], those observed for the $v_{6}$ mode in jet-cooled conditions (Fig. 3c) are quite similar and follow the same rating, suggesting that the barriers are enough high that no interconversion takes place in the collision zone before the expansion. Moreover, although Ar is a seeding gas often used to favor the most stable species, no enhancement of $\mathrm{C} 1$ conformer is evidenced, probably due to the low backing pressures (about 100 mbar) of Jet-AILES. In the mid-IR, a conformational assignment of the 40 observed Q-branches is tentatively proposed and summarized in Table 2. The four conformers signatures are individually assigned for some mid-IR vibrational modes such as the $v_{21}$ in-plane ring bending, $v_{27} \mathrm{CH}_{3}$ wagging/in-plane $\mathrm{CH}$ bending or $v_{28} \mathrm{C}-\mathrm{O}$ symmetric stretching. Nevertheless, due to a strong congestion of the spectrum because of overlapping bands, the full conformational discrimination is delicate for some modes such as the $v_{18}$ in-plane ring bending, $v_{33} \mathrm{CH}_{3}$ scissoring or $v_{35-37} \mathrm{C}-\mathrm{C}$ stretchings.

For the 4MP isomer, two stable conformers 4MP-C1 and 4MP-C2 are expected corresponding respectively to the cis and the trans orientations of the $-\mathrm{OCH}_{3}$ and $-\mathrm{OH}$ groups (see Fig. 3a). Only the most stable $\mathrm{C} 1$ conformer (cis) was observed by mmw spectroscopy. The $\mathrm{C} 2$ conformer (trans) has a permanent dipole moment five times weaker than $\mathrm{C} 1$ and this is likely why it was not detected.[9] This problem does not arise with the 4MP rovibrational Jet-AILES spectrum, which reveals two Q-branches with similar intensities linked to the strong transition moment of the $v_{5}$ out-of-plane $\mathrm{OH}$ bending mode of 4MP-C1 and 4MP-C2 at $269.1 \mathrm{~cm}^{-1}$ and $259.9 \mathrm{~cm}^{-1}$, respectively (see Fig. 3c). The $9.2 \mathrm{~cm}^{-1}$ separation between the Q-branches of the two conformers is in rather good agreement with the B3LYP/cc-pVTZ harmonic calculations which predict 4MP-C2 red-shifted from 4MP-C1 by $7 \mathrm{~cm}^{-1}$ (see Table 3). In the absence of other intense fundamentals in the out-of-plane $\mathrm{OH}$ bending mode region, the weaker satellite bands observed on the blue side of the $v_{5}$ band are probably due to hot bands of the type $(n+1) v_{5} \leftarrow n v_{5}$ with $n=0-2$. This is the case of 

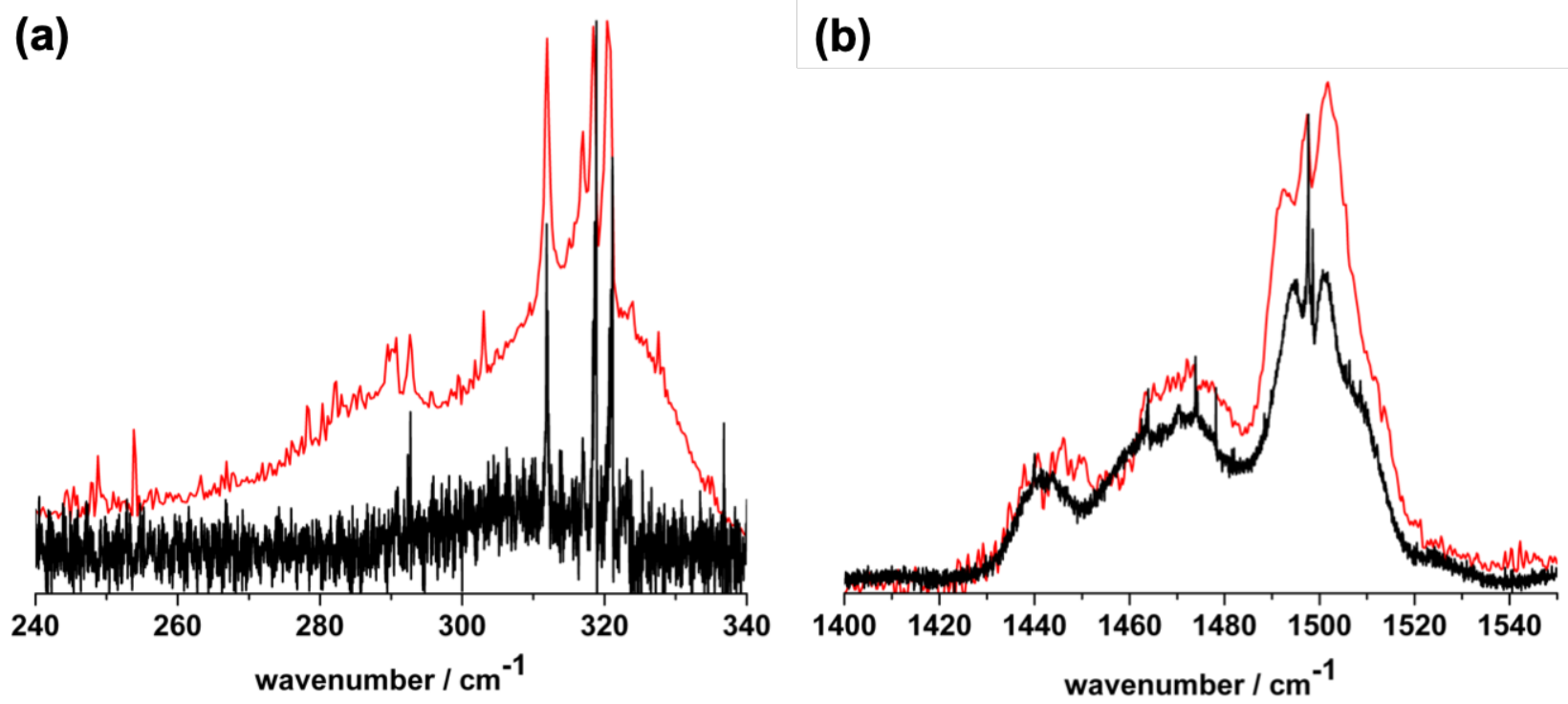

Fig. 2. Comparison of 3MP FT spectra recorded at room temperature[7] (in red) and in supersonic-jet conditions with a $5 \mathrm{slm}$ flow of Ar buffer gas (in black). Fig. 2a: Zoom into a portion of the far-IR region $\left(240-340 \mathrm{~cm}^{-1}\right) ;$ Fig. $2 b$ : Zoom onto a portion of the mid-IR region (1400-1550 $\left.\mathrm{cm}^{-1}\right)$. For visibility, the four spectra are normalized to the Q-branch of strongest intensity.

the series observed for 4MP-C2 at 259.92, 260.61 and 261.37 $\mathrm{cm}^{-1}$ which displays a diagonal anharmonicity $\chi_{55}$ of $0.34(1)$ $\mathrm{cm}^{-1}$. Weaker Q-branches were also observed at higher frequencies and were assigned to the $v_{7}$ in-plane $-\mathrm{CO}$ bending and $v_{10}$ out-of-plane $-\mathrm{CH}$ bending modes of $4 \mathrm{MP}$. For these modes, it was not possible to discriminate the two conformers. In the mid-IR, 14 bands were measured in jet-cooled conditions. The vibrational signatures of the 4MP-C1 and 4MP-C2 conformers are however clearly discriminated for some specific modes such as the $v_{21} \mathrm{O}-\mathrm{CH}_{3}$ stretching, $v_{27} \mathrm{CH}_{3}$ wagging/in-plane $\mathrm{CH}$ bending or $v_{35}$ in-plane $\mathrm{CH}$ bending.

On the grounds of 80 previous vibrational FTIR assignments reported in Tables 1, 2 and 3, the average error between observed and calculated anharmonic frequencies could be estimated to about $15.7 \%$ (11.4\% for harmonic calculations) in the far-IR domain and about $0.5 \%$ (2.0\% for harmonic calculations) in the mid-IR domain. Moreover, in the case of a full conformational landscape assignment $\left(v_{6}, v_{21}, v_{27}, v_{28}\right.$ modes for 3MP and $v_{5}, v_{21}, v_{27}, v_{31}, v_{35}$ modes for 4MP), we considered the differences between the highest and lowest calculated frequency of the stable conformers for a given vibrational mode, the RFD, which display far-IR average errors of about $470 \%$ with anharmonic calculations ( $150 \%$ for harmonic) with respect to the experimental ones. In the mid-IR, the average errors are about $40 \%$ both for harmonic and anharmonic calculations. The reliability of this parameter is crucial to validate the vibrational assignments. We compared systematically the experimental RFD (especially in the case of a full conformational assignment) to the calculated harmonic and anharmonic ones to choose the best type of calculation. The largest average errors evidenced in the far-IR confirm that low order perturbation theory calculations (VPT2) lack of accuracy in the case of low-lying large amplitude motions.[24] In these cases, since the harmonic (quadratic) term is the leading term in the series expansion of the potential, harmonic frequency values may be preferred. On the contrary, in the mid-IR, anharmonic calculations improve the prediction of the MP vibrational band centers and facilitate the conformational assignment.

\section{B. High resolution SPIRALES spectra}

Two types of vibrations of the MP compounds are accessible within the spectral range of the available SPIRALES EC-QCLs: the in-plane ring bending mode $\left(v_{18}\right)$ and the $\mathrm{C}-\mathrm{C}$ ring stretching modes $\left(v_{36}, v_{37}\right)$ in the $930-960 \mathrm{~cm}^{-1}$ and $1580-1640$ $\mathrm{cm}^{-1}$ regions, respectively. The Q-branches identified in the Jet-AILES spectra enable to evaluate more precisely which MPs rovibrational signatures can be reached with the SPIRALES setup. As can be seen in Fig.4b, only the 3MP isomer displays intense bands likely to be rotationally resolved in these regions. We thus present hereafter the results obtained from jet-cooled QCL spectroscopy of 3MP.

\section{B.1. Rovibrational analysis of the $v_{18}$ band of $3 M P$}

In the spectrum recorded by the SPIRALES setup around 950 $\mathrm{cm}^{-1}$, the rotational structure in the $v_{18}$ band of $3 \mathrm{MP}$ is indeed resolved: two Q-branches spaced by $0.07 \mathrm{~cm}^{-1}$ (Fig. 5b) are clearly observed, which suggests the presence of two conformers of 3MP. The bands are assigned to the $v_{18}$ band of 3MP-C1 and 3MP-C4 on grounds of anharmonic calculations which predict these conformers bands very close in frequency, and about $20 \mathrm{~cm}^{-1}$ higher in frequency than 3MP-C2 and 3MP-C3. Two weaker bands appear red shifted by $0.45 \mathrm{~cm}^{-1}$ from the two fundamental Q-branches. These weaker features were already observed, although unresolved, on the Jet-AILES spectrum (see Fig. 5a). The intensity ratio between these features and the assigned fundamental Q-branch of 3MP-C1 is 0.34, while it is 0.2 in the SPIRALES spectrum, a ratio 1.7 times lower than that of Jet-AILES spectrum. Such findings are in agreement 

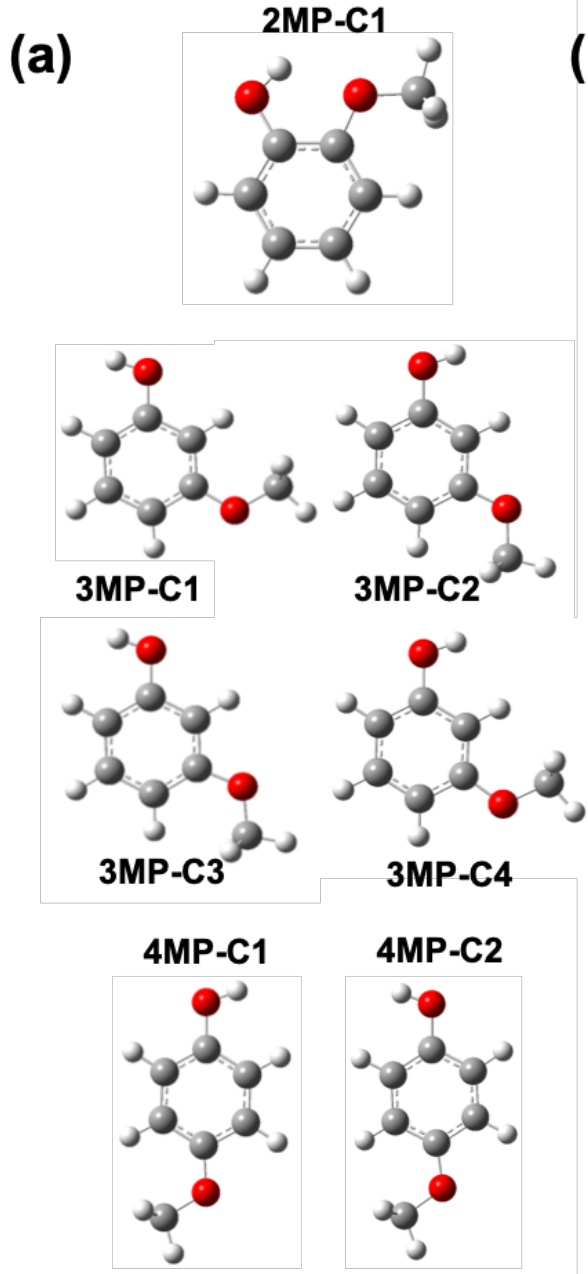
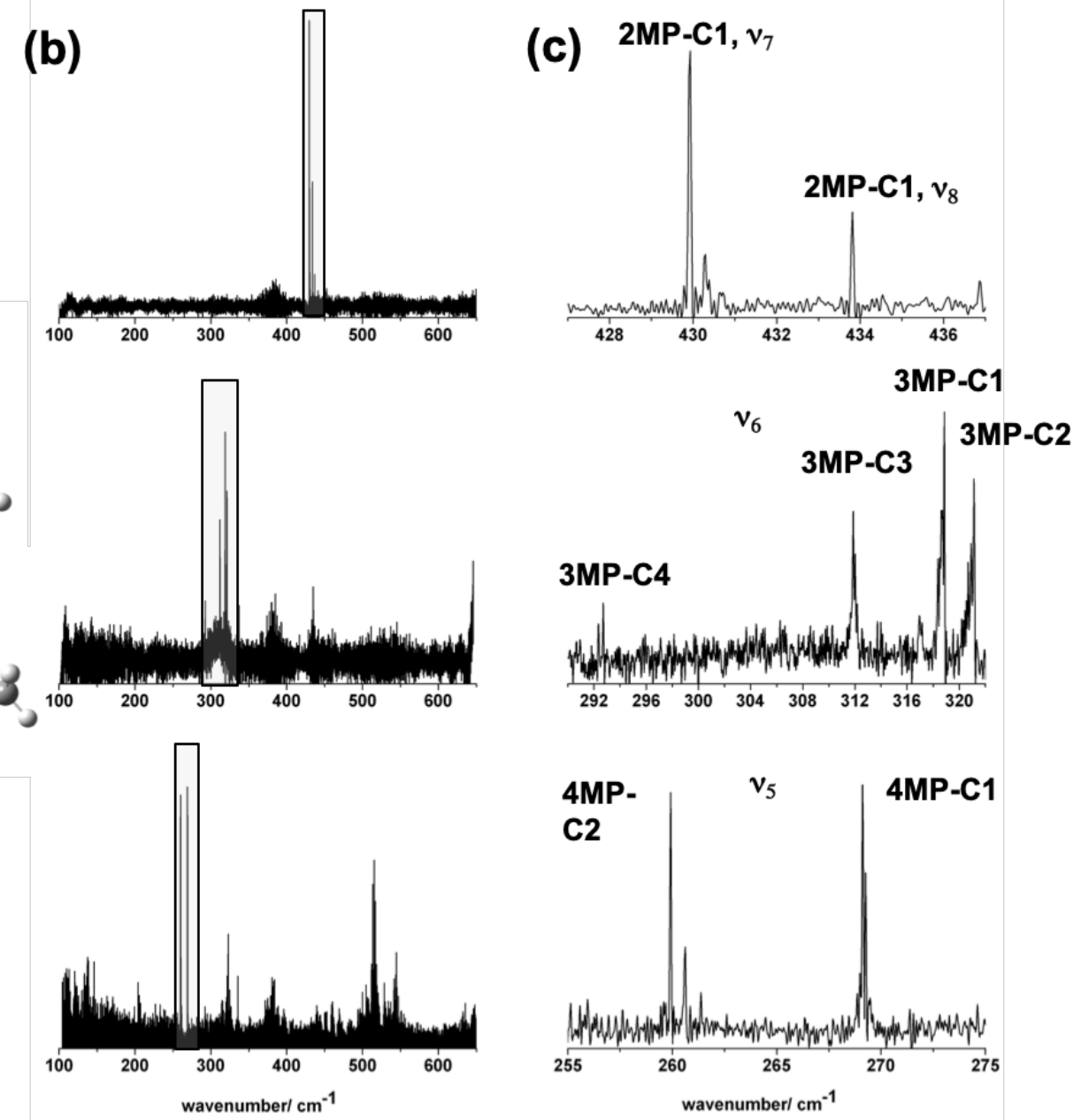

Fig. 3. Stable conformers and far-IR Jet-AILES spectra of the three MP isomers (2MP, 3MP, and 4MP, from top to bottom). Fig. 3a: Optimized structures of the identified stable conformers obtained from calculations at the B3LYP/cc-pVTZ level of theory and labeled in accordance with Ref. [8, 9]; Fig. 3b: Full Jet-AILES far-IR absorbance spectra measured using 5 slm of Ar buffer gas; Fig. $3 c$ : zoom on the strongest Q-branches associated with the $c$-type out-of-plane-OH bending modes (identified by a black rectangle on the full-range spectra).

with hot band features which are expected to be weaker under the pulsed expansion conditions of SPIRALES (more efficient vibrational cooling at a higher backing pressure) leading to a lower temperature of the pulsed jet compared to the continuous expansion of Jet-AILES. In the following paragraphs, we will define the $R$ ratio by:

$$
R=\frac{\left(I_{\mathrm{UB}} / I_{\mathrm{FB}}\right)_{\mathrm{Jet}-\mathrm{AILES}}}{\left(I_{\mathrm{UB}} / I_{\mathrm{FB}}\right)_{\text {SPIRALES }}}
$$

where UB and FB refer to the undefined band and the fundamental band, respectively. If $R<1$, an undefined band observed in the SPIRALES spectrum is more intense than in the Jet-AILES spectrum, relative to the fundamental band, and is thus unlikely to be a hot band.

Using as initial set of parameters the $v_{18}=1$ scaled rotational constants from anharmonic B3LYP/cc-pVTZ predictions and GS experimental constants [8], the rovibrational spectrum of the $v_{18}$ band of both 3MP-C1 and 3MP-C4 conformers has been assigned using the PGOPHER[27] and LWWa [28] programs. A total of 766 3MP-C1 and 179 3MP-C4 rovibrational transitions corresponding respectively to 152 and 55 different frequencies have been assigned (see supplementary materials Tables S9-S10 for the list of assigned transitions). The difference between the number of assigned transitions and the number of different frequencies is due to unresolved asymmetric splitting, overlap of $a$ - and $b$-type transitions, and $K_{a}$ clustering. Spectroscopic parameters were derived from a fit performed using the Pickett suite of programs [29] using a Watson-type semi-rigid rotor model ( $A$-reduction in the $\mathrm{I}^{r}$ representation) developed up to quartic centrifugal distortion (CD) constants (Table 4). All CD terms in $v_{18}=1$ except for $\Delta_{J}$ were kept fixed at the GS values. Pure rotational transitions from Ref. [8] and rovibrational transitions in the $v_{18}$ band from this work were included in the fit. Since multiple transitions are assigned to the same frequency, each line has been weighted according to its expected intensity at $30 \mathrm{~K}$. A unique uncertainty on frequency of 0.0015 
Table 1. Experimental $\left(v_{\text {exp }}\right)$ and calculated ( $v_{\text {harm }}$ and $v_{\text {anharm }}$ ) values at the B3LYP/cc-pVTZ level of the vibrational bands centers of 2MP with the vibrational assignments. All frequencies were measured from the Q-branches observed on the Jet-AILES spectra.

\begin{tabular}{|c|c|c|c|c|c|c|c|}
\hline & $v_{\text {exp }}$ & Mode & Symmetry & Conformer & $v_{\text {harm }}$ & $v_{\text {anharm }}$ & Description \\
\hline \multirow{17}{*}{$\sum_{i}^{e}$} & 429.9 & $v_{7}$ & A" & $\mathrm{C} 1$ & 446.9 & 313.0 & -OH/-CH in-phase out-of-plane bending \\
\hline & 433.8 & $v_{8}$ & A" & $\mathrm{C} 1$ & 472.2 & 573.6 & $-\mathrm{OH} /-\mathrm{CH}$ out-of-phase out-of-plane bending \\
\hline & 911.1 & $v_{18}$ & A" & $\mathrm{C} 1$ & 931.8 & 921.8 & $\mathrm{CH}$ out-of-plane bending \\
\hline & 1053.5 & $v_{21}$ & $A^{\prime}$ & $\mathrm{C} 1$ & 1068.1 & 1045.3 & in-plane ring bending \\
\hline & 1113.7 & $v_{22}$ & $A^{\prime}$ & $\mathrm{C} 1$ & 1133.9 & 1113.4 & $-\mathrm{CH}$ in-plane bending \\
\hline & 1181.5 & $v_{25}$ & A" & $\mathrm{C} 1$ & 1199.0 & 1170.2 & $-\mathrm{CH}$ in-plane bending / $-\mathrm{CH}_{3}$ wagging \\
\hline & 1212.6 & $v_{26}$ & $A^{\prime}$ & $\mathrm{C} 1$ & 1231.0 & 1209.1 & $-\mathrm{OH} /-\mathrm{OCH}$ in-plane bending \\
\hline & 1230.9 & $v_{27}$ & $A^{\prime}$ & $\mathrm{C} 1$ & 1252.1 & 1219.1 & C-O stretching \\
\hline & 1265.1 & $v_{28}$ & $A^{\prime}$ & $\mathrm{C} 1$ & 1288.6 & 1256.8 & $\mathrm{C}-\mathrm{O}$ stretching \\
\hline & 1308.0 & $v_{29}$ & $A^{\prime}$ & $\mathrm{C} 1$ & 1335.0 & 1307.0 & $-\mathrm{CH}$ in-plane bending \\
\hline & 1461.3 & $v_{31}$ & $A^{\prime}$ & $\mathrm{C} 1$ & 1481.7 & 1444.3 & $-\mathrm{CH}_{3}$ scissoring/- $\mathrm{CH}$ in-plane bending \\
\hline & 1471.4 & $v_{32}$ & A" & $\mathrm{C} 1$ & 1492.9 & 1448.5 & $-\mathrm{CH}_{3}$ scissoring \\
\hline & 1477.4 & $v_{33}$ & $A^{\prime}$ & $\mathrm{C} 1$ & 1503.6 & 1464.2 & - $\mathrm{CH}$ in-plane bending \\
\hline & 1478.6 & $v_{34}$ & $A^{\prime \prime}$ & $\mathrm{C} 1$ & 1511.1 & 1475.2 & $-\mathrm{CH}_{3}$ scissoring \\
\hline & 1508.4 & $v_{35}$ & $A^{\prime}$ & $\mathrm{C} 1$ & 1539.1 & 1501.2 & - $\mathrm{CH}$ in-plane bending \\
\hline & 1611.0 & $v_{36}$ & $A^{\prime}$ & $\mathrm{C} 1$ & 1637.4 & 1597.7 & C-C stretching \\
\hline & 1616.7 & $v_{37}$ & $A^{\prime}$ & $\mathrm{C} 1$ & 1653.0 & 1609.7 & C-C stretching \\
\hline
\end{tabular}

$\mathrm{cm}^{-1}$ was used for all infrared lines. For both conformers, the derived GS spectroscopic parameters are identical to those previously reported,[8] a likely reflection of the higher resolution, higher range of covered quantum numbers, and higher number of observed transitions in that study. In $v_{18}=1$, the derived rotational constants are in excellent agreement with the predicted, scaled, values (to better than 1\%), a confirmation of the correct assignment of the 3MP-C1 and 3MP-C4 conformers. With a reduced standard deviation 0.95 and 1.09 for 3MP-C1 and 3MP-C4, respectively, all the assigned lines are reproduced at the experimental accuracy.

The Jet-AILES and SPIRALES experimental spectra are compared to a Pgopher simulation (see Fig. 5c) based on the adjusted molecular parameters using a rotational temperature of $30 \mathrm{~K}$ and a full-width at half-maximum (FWHM) of the rotational transitions of $0.004 \mathrm{~cm}^{-1}$, two parameters found to nicely reproduce the line profiles. However the relative intensity ratio of the $\mathrm{C} 1$ and $\mathrm{C} 4$ conformers differ from what should be expected from natural abundances previously determined [8] and predicted band intensities from the B3LYP/cc-pVTZ harmonic calculation: when taking into account both these parameters ( $45 \%$ and $8 \%$ population and $I=73$ and $35 \mathrm{~km} / \mathrm{mol}$ for 3MP-C1 and 3MP-C4, respectively), the 3MP-C4 Q-branch intensity is underestimated in the simulation compared to what is observed in the experiment. Instead, a reasonable simulation is obtained by using the same IR activities for the $v_{18}$ band of the two conformers (thus only taking into account the relative population).

From this analysis, we can confirm that the DFT calculations provide a reliable base for conformational assignment by frequency differences: the predicted harmonic and anharmonic frequencies were in reasonable agreement with the experiment and the frequency difference for a given mode between stable conformers provided accurate grounds for their experimental identification (see Fig. S1). The calculated intensities, both harmonic and anharmonic, however, appear less useful to guide conformational assignment.

\section{B.2. Vibrational analysis of the $v_{36}$ and $v_{37}$ modes of $3 M P$}

Fig. 6 displays SPIRALES measurements of 3MP recorded in the $1600-1635 \mathrm{~cm}^{-1}$ range near the Q-branches identified on the Jet-AILES spectrum. Due to the higher resolution and sensitivity of the SPIRALES setup, narrower Q-branches $\left(\Delta v_{\mathrm{FWHM}}\right.$ $=0.15 \mathrm{~cm}^{-1}$ ) with better SNR are observed allowing to refine conformational assignments, particularly in the case of the $v_{37}$ band. While for $v_{18}$ mode, the harmonic and anharmonic predictions were consistent in terms of conformer frequency order, and the main change was thus in absolute frequency, for $v_{36}$ and $v_{37}$ the frequency difference between conformers is significantly different between the calculations (see Fig. S2). Interestingly, the best qualitative agreement is obtained using the harmonic frequencies which will thus serve as a basis for the following assignments.

In the $v_{36}$ band region (Fig. 6a), the broad Q-branch observed in the Jet-AILES spectrum is partially resolved in the SPIRALES one with two bands at 1602.63 and $1602.80 \mathrm{~cm}^{-1}$ accompanied by weak satellites on the blue side (Fig. 6). Besides, no other band has been detected in the $1590-1610 \mathrm{~cm}^{-1}$ range. Based on the expected frequency difference between conformers, we propose to assign these two bands to the 3MP-C2 and $3 \mathrm{MP}-\mathrm{C} 4$ conformers. The 3MP-C1 and 3MP-C 3 conformers expected at lower frequencies remain not observed.

The $v_{37}$ band region, richer in structures, displays 6 Qbranches (Fig. 6b) whereas only four are expected. The bands appear as three sets of doublets, each composed of a strong band and a weaker satellite on the blue side (at 1624.10/1624.79, $1629.25 / 1630.01$, and $1632.07 / 1632.49 \mathrm{~cm}^{-1}$ ). Under the hypothesis that the weaker bands could arise from hot bands, we calculated the $R$ ratio (see Eq.1) for each doublet which takes values of $0.4,0.7$, and 2.4 for the lines at $1624.79,1630.01$, and $1632.49 \mathrm{~cm}^{-1}$, respectively. On these grounds, we argue that the band at $1624.79 \mathrm{~cm}^{-1}$ can not be a hot band of the 
Table 2. Experimental ( $\left.v_{\text {exp }}\right)$ and calculated ( $v_{\text {harm }}$ and $v_{\text {anharm }}$ ) values at the B3LYP/cc-pVTZ level of the vibrational bands centers of 3MP with the vibrational and conformational assignments. All frequencies were measured from the Q-branches observed on the Jet-AILES spectra except those, where the $v_{\exp }$ values are marked with a star, associated with the SPIRALES measurements. In the case $v_{\text {exp }, 18}$, the fitted vibrational band centers are reported (see Table 4 for more digits).

\begin{tabular}{|c|c|c|c|c|c|c|c|}
\hline & $v_{\text {exp }}$ & Mode & Symmetry & Conformer & $v_{\text {harm }}$ & $v_{\text {anharm }}$ & Description \\
\hline \multirow{46}{*}{$\sum_{m}$} & 292.7 & $v_{6}$ & A" & $\mathrm{C} 4$ & 332.2 & 299.4 & -OH out-of-plane bending \\
\hline & 311.9 & $v_{6}$ & A" & $\mathrm{C} 3$ & 349.3 & 345.0 & -OH out-of-plane bending \\
\hline & 318.9 & $v_{6}$ & A" & $\mathrm{C} 1$ & 354.8 & 377.3 & -OH out-of-plane bending \\
\hline & 321.1 & $v_{6}$ & A" & $\mathrm{C} 2$ & 360.8 & 359.3 & -OH out-of-plane bending \\
\hline & $949.72^{*}$ & $v_{18}$ & $A^{\prime}$ & $\mathrm{C} 1$ & 964.5 & 946.0 & in-plane ring bending \\
\hline & $949.66^{*}$ & $v_{18}$ & $A^{\prime}$ & $\mathrm{C} 4$ & 964.5 & 946.1 & in-plane ring bending \\
\hline & 1053.4 & $v_{21}$ & $A^{\prime}$ & $\mathrm{C} 1$ & 1065.9 & 1040.4 & in-plane ring bending \\
\hline & 1061.9 & $v_{21}$ & $A^{\prime}$ & $\mathrm{C} 2$ & 1075.8 & 1050.4 & in-plane ring bending \\
\hline & 1058.3 & $v_{21}$ & $A^{\prime}$ & $\mathrm{C} 3$ & 1071.2 & 1046.2 & in-plane ring bending \\
\hline & 1055.8 & $v_{21}$ & $A^{\prime}$ & $\mathrm{C} 4$ & 1068.5 & 1043.0 & in-plane ring bending \\
\hline & 1150.3 & $v_{24}$ & $A^{\prime}$ & $\mathrm{C} 1$ & 1175.0 & 1146.9 & $-\mathrm{CH}$ in-plane bending \\
\hline & 1150.9 & $v_{24}$ & $A^{\prime}$ & $\mathrm{C} 2$ & 1178.7 & 1145.7 & $-\mathrm{CH}$ in-plane bending \\
\hline & 1144.5 & $v_{23}$ & $A^{\prime}$ & $\mathrm{C} 3$ & 1169.1 & 1133.4 & $-\mathrm{CH}_{3}$ rocking \\
\hline & 1153.9 & $v_{23}$ & A" & $\mathrm{C} 4$ & 1172.3 & 1150.8 & $-\mathrm{CH}_{3}$ rocking \\
\hline & 1190.9 & $v_{25}$ & $A^{\prime}$ & $\mathrm{C} 4$ & 1195.9 & 1182.7 & - $\mathrm{CH}$ in-plane bending \\
\hline & 1161.3 & $v_{25}$ & $A^{\prime}$ & $\mathrm{C} 1 / \mathrm{C} 2$ & $1183.3 / 1192.6$ & $1156.6 / 1166.1$ & $-\mathrm{CH}$ in-plane bending \\
\hline & 1175.5 & $v_{26}$ & $A^{\prime}$ & $\mathrm{C} 2$ & 1198.4 & 1178.1 & $-\mathrm{CH}_{3}$ wagging $-\mathrm{OH}$ in-plane bending \\
\hline & 1176.0 & $v_{26}$ & $A^{\prime}$ & $\mathrm{C} 1$ & 1206.4 & 1177.8 & $-\mathrm{CH}_{3}$ wagging $-\mathrm{OH}$ in-plane bending \\
\hline & 1205.1 & $v_{27}$ & $A^{\prime}$ & $\mathrm{C} 2$ & 1227.9 & 1203.1 & $-\mathrm{CH}_{3}$ wagging $-\mathrm{CH}$ in-plane bending \\
\hline & 1206.6 & $v_{27}$ & $A^{\prime}$ & $\mathrm{C} 4$ & 1230.1 & 1203.2 & $-\mathrm{CH}_{3}$ wagging $-\mathrm{CH}$ in-plane bending \\
\hline & 1217.9 & $v_{27}$ & $A^{\prime}$ & $\mathrm{C} 1$ & 1236.7 & 1220.7 & $-\mathrm{CH}_{3}$ wagging $-\mathrm{CH}$ in-plane bending \\
\hline & 1226.0 & $v_{27}$ & $A^{\prime}$ & $\mathrm{C} 3$ & 1244.1 & 1231.1 & $-\mathrm{CH}_{3}$ wagging $-\mathrm{CH}$ in-plane bending \\
\hline & 1298.7 & $v_{28}$ & $A^{\prime}$ & $\mathrm{C} 1$ & 1317.4 & 1288.4 & C-O symmetric stretching \\
\hline & 1296.6 & $v_{28}$ & $A^{\prime}$ & $\mathrm{C} 2$ & 1320.1 & 1287.3 & C-O symmetric stretching \\
\hline & 1292.3 & $v_{28}$ & $A^{\prime}$ & $\mathrm{C} 3$ & 1317.4 & 1283.5 & C-O symmetric stretching \\
\hline & 1293.7 & $v_{28}$ & $A^{\prime}$ & $\mathrm{C} 4$ & 1315.2 & 1285.0 & C-O symmetric stretching \\
\hline & 1306.8 & $v_{29}$ & $A^{\prime}$ & $\mathrm{C} 1$ & 1337.5 & 1311.5 & $-\mathrm{CH}$ in-plane bending \\
\hline & 1304.2 & $v_{29}$ & $A^{\prime}$ & $\mathrm{C} 3$ & 1335.5 & 1307.4 & $-\mathrm{CH}$ in-plane bending \\
\hline & 1330.2 & $v_{30}$ & $A^{\prime}$ & $\mathrm{C} 1$ & 1365.7 & 1332.1 & $-\mathrm{CH}$ in-plane bending \\
\hline & 1331.6 & $v_{30}$ & $A^{\prime}$ & $\mathrm{C} 3$ & 1361.9 & 1333.3 & $-\mathrm{CH}$ in-plane bending \\
\hline & 1439.8 & $v_{31}$ & $A^{\prime}$ & $\mathrm{C} 1$ & 1474.2 & 1434.6 & $-\mathrm{CH}_{3}$ wagging \\
\hline & 1440.0 & $v_{31}$ & $A^{\prime}$ & $\mathrm{C} 3$ & 1477.0 & 1439.5 & $-\mathrm{CH}_{3}$ wagging \\
\hline & 1462.5 & $v_{33} / v_{34}$ & $A^{\prime}$ & $\mathrm{C} 2 / \mathrm{C} 4$ & $1496.7 / 1477.0$ & 1463.8 & $-\mathrm{CH}_{3}$ scissoring/C-C stretching \\
\hline & 1463.9 & $v_{33}$ & $A^{\prime}$ & $\mathrm{C} 1 / \mathrm{C} 3$ & $1505.0 / 1505.9$ & $1499.3 / 1464.7$ & $-\mathrm{CH}_{3}$ scissoring \\
\hline & 1473.9 & $v_{34}$ & $A^{\prime}$ & $\mathrm{C} 2$ & 1510.4 & 1474.2 & C-C stretching \\
\hline & 1478.2 & $v_{34}$ & $A^{\prime}$ & $\mathrm{C} 1$ & 1517.8 & 1484.6 & C-C stretching \\
\hline & 1488.4 & $v_{34}$ & $A^{\prime}$ & $\mathrm{C} 3$ & 1518.4 & 1486.2 & $\mathrm{C}-\mathrm{C}$ stretching \\
\hline & 1497.6 & $v_{35}$ & $A^{\prime}$ & $\mathrm{C} 3 / \mathrm{C} 4$ & $1529.1 / 1540.8$ & $1499.3 / 1499.0$ & C-C stretching \\
\hline & 1498.5 & $v_{35}$ & $A^{\prime}$ & $\mathrm{C} 1$ & 1529.7 & 1501.4 & $\mathrm{C}-\mathrm{C}$ stretching \\
\hline & 1506.4 & $v_{35}$ & $A^{\prime}$ & $\mathrm{C} 2$ & 1540.8 & 1506.3 & $\mathrm{C}-\mathrm{C}$ stretching \\
\hline & $1602.63^{*}$ & $v_{36}$ & $A^{\prime}$ & $\mathrm{C} 2$ & 1640.4 & 1600.2 & $\mathrm{C}-\mathrm{C}$ stretching \\
\hline & $1602.80^{*}$ & $v_{36}$ & $A^{\prime}$ & $\mathrm{C} 4$ & 1640.5 & 1606.1 & C-C stretching \\
\hline & $1624.10^{*}$ & $v_{37}$ & $A^{\prime}$ & $\mathrm{C} 2$ & 1652.0 & 1618.7 & C-C stretching \\
\hline & $1624.79^{*}$ & $v_{37}$ & $A^{\prime}$ & $\mathrm{C} 4$ & 1652.7 & 1607.3 & C-C stretching \\
\hline & $1629.25^{*}$ & $v_{37}$ & $A^{\prime}$ & $\mathrm{C} 1$ & 1656.7 & 1619.8 & $\mathrm{C}-\mathrm{C}$ stretching \\
\hline & $1632.07^{*}$ & $v_{37}$ & $\mathrm{~A}^{\prime}$ & $\mathrm{C} 3$ & 1662.5 & 1623.7 & $\mathrm{C}-\mathrm{C}$ stretching \\
\hline
\end{tabular}

one at $1624.10 \mathrm{~cm}^{-1}(R<<1)$. With an $R$ value significantly above 1 , the $1632.49 \mathrm{~cm}^{-1}$ band is tentatively assigned to a hot band of the one at $1632.07 \mathrm{~cm}^{-1}$, although the modes involved remain undetermined. The $1630.01 \mathrm{~cm}^{-1}$, however, is more questionable since the $R$ value is relatively close to 1 . Because of possible baseline errors in the FTIR spectrum and in the uncertainty inherent with the $\mathrm{R}$ determination, the band could either arise from a hot or a cold (including overtone/combination) band. The harmonic calculation provide solid ground for the spectral assignment, as in the $v_{36}$ band region (see Fig. S2). The close Q-branches at 1624.10 and $1624.79 \mathrm{~cm}^{-1}$ are assigned to $3 \mathrm{MP}-\mathrm{C} 2$ and $3 \mathrm{MP}-\mathrm{C} 4$ conformers while the highest frequency 
Table 3. Experimental ( $\left.v_{\text {exp }}\right)$ and calculated ( $v_{\text {harm }}$ and $v_{\text {anharm }}$ ) values at the B3LYP/cc-pVTZ level of the vibrational bands centers of 4MP with the vibrational and conformational assignments. All frequencies were measured from the Q-branches observed on the Jet-AILES spectra.

\begin{tabular}{|c|c|c|c|c|c|c|c|}
\hline & $v_{\exp }$ & Mode & Symmetry & Conformer & $v_{\text {harm }}$ & $v_{\text {anharm }}$ & Description \\
\hline \multirow{18}{*}{$\sum_{f}$} & 259.9 & $v_{5}$ & A" & $\mathrm{C} 2$ & 302.8 & 301.2 & -OH out-of-plane bending \\
\hline & 269.1 & $v_{5}$ & A" & $\mathrm{C} 1$ & 309.8 & 370.5 & -OH out-of-plane bending \\
\hline & 322.9 & $v_{7}$ & $A^{\prime}$ & $\mathrm{C} 1$ & 381.1 & 378.6 & -CO in-plane bending \\
\hline & 515.4 & $v_{10}$ & A" & $\mathrm{C} 1 / \mathrm{C} 2$ & $527.3 / 526.6$ & $528.1 / 525.7$ & -CH out-of-plane bending \\
\hline & 1057.1 & $v_{21}$ & $A^{\prime}$ & $\mathrm{C} 1$ & 1068.5 & 1041.4 & $\mathrm{O}-\mathrm{CH}_{3}$ stretching \\
\hline & 1057.4 & $v_{21}$ & $A^{\prime}$ & $\mathrm{C} 2$ & 1068.7 & 1042.2 & $\mathrm{O}-\mathrm{CH}_{3}$ stretching \\
\hline & 1097.5 & $v_{22}$ & $A^{\prime}$ & $\mathrm{C} 1 / \mathrm{C} 2$ & $1124.9 / 1126.1$ & $1104.7 / 1103.3$ & -CH in-plane bending \\
\hline & 1168.2 & $v_{24}$ & $A^{\prime}$ & $\mathrm{C} 1$ & 1186.7 & 1150.1 & $-\mathrm{OH} /-\mathrm{CH}$ in-plane bending \\
\hline & 1177.4 & $v_{26}$ & $A^{\prime}$ & $\mathrm{C} 2$ & 1207.3 & 1170.6 & $-\mathrm{CH}_{3}$ wagging $-\mathrm{OH}$ in-plane bending \\
\hline & 1241.3 & $v_{27}$ & $A^{\prime}$ & $\mathrm{C} 1$ & 1264.8 & 1229.0 & $-\mathrm{CH}_{3}$ wagging $-\mathrm{CH}$ in-plane bending \\
\hline & 1247.2 & $v_{27}$ & $A^{\prime}$ & $\mathrm{C} 2$ & 1268.7 & 1237.9 & $-\mathrm{CH}_{3}$ wagging $-\mathrm{CH}$ in-plane bending \\
\hline & 1338.4 & $v_{30}$ & $A^{\prime}$ & $\mathrm{C} 2$ & 1370.2 & 1340.2 & $-\mathrm{CH}$ in-plane bending \\
\hline & 1443.2 & $v_{31}$ & $A^{\prime}$ & $\mathrm{C} 1$ & 1475.7 & 1434.1 & $-\mathrm{CH}_{3}$ wagging $-\mathrm{CH}$ in-plane bending \\
\hline & 1440.9 & $v_{31}$ & $A^{\prime}$ & $\mathrm{C} 2$ & 1472.4 & 1432.1 & $-\mathrm{CH}_{3}$ wagging $-\mathrm{CH}$ in-plane bending \\
\hline & 1462.9 & $v_{33}$ & A" & $\mathrm{C} 1$ & $1493.7 / 1493.4$ & $1458.0 / 1455.4$ & $-\mathrm{CH}_{3}$ twisting \\
\hline & 1474.1 & $v_{34}$ & $A^{\prime}$ & $\mathrm{C} 1 / \mathrm{C} 2$ & $1509.1 / 1508.8$ & 1476.4/1477.2 & $-\mathrm{CH}_{3}$ scissoring \\
\hline & 1517.4 & $v_{35}$ & $A^{\prime}$ & $\mathrm{C} 1$ & 1449.4 & 1511.0 & $-\mathrm{CH}$ in-plane bending \\
\hline & 1516.0 & $v_{35}$ & $A^{\prime}$ & $\mathrm{C} 2$ & 1449.3 & 1509.8 & - $\mathrm{CH}$ in-plane bending \\
\hline
\end{tabular}

Table 4. Summary of the spectroscopic parameters of 3MP-C1 and 3MP-C4 from a fit of the literature pure rotational GS transitions[8] and rovibrational transitions in the $v_{18}$ band (this work). Pertinent parameters to the fit (number of fitted transitions, range of observed quantum numbers, rms and standard deviation) are also reported. Owing to the low rotational temperature in the supersonic expansion, most of the quartic centrifugal distortion constants in $v_{18}=1$ were fixed to the GS values as indicated by the brackets. Values are in MHz unless otherwise noted.

\begin{tabular}{|c|c|c|c|c|}
\hline \multirow[t]{2}{*}{ Constant } & \multicolumn{2}{|c|}{ 3MP-C1 } & \multicolumn{2}{|c|}{ 3MP-C4 } \\
\hline & $v=0$ & $v_{18}=1$ & $v=0$ & $v_{18}=1$ \\
\hline$E^{a}$ & & $949.72714(25)$ & & $949.65653(48)$ \\
\hline$A$ & $2840.8815(55)$ & $2840.35(32)$ & $2847.05511(54)$ & $2846.19(39)$ \\
\hline$B$ & $1303.5274(14)$ & $1300.79(53)$ & $1298.12761(13)$ & $1295.29(11)$ \\
\hline C & $898.98216(10)$ & $898.120(25)$ & $897.065125(38)$ & $896.464(45)$ \\
\hline$\Delta_{J} \times 10^{3}$ & $0.05094(36)$ & $0.155(11)$ & $0.0503425(72)$ & $0.201(20)$ \\
\hline$\Delta_{J K} \times 10^{3}$ & $-0.0979(24)$ & {$[-0.0979]$} & $-0.091482(53)$ & {$[-0.091484]$} \\
\hline$\Delta_{K} \times 10^{3}$ & $0.402(15)$ & {$[0.4026]$} & $0.38344(36)$ & {$[0.38337]$} \\
\hline$\delta_{J} \times 10^{6}$ & $18.21(18)$ & {$[18.210]$} & $17.9048(36)$ & {$[17.9047]$} \\
\hline$\delta_{K} \times 10^{6}$ & $79.7(11)$ & {$[79.71]$} & $81.033(48)$ & {$[81.030]$} \\
\hline$N^{b}$ & $1776^{c}$ & $766^{d}$ & 3913 & 179 \\
\hline$n^{b}$ & $482^{c}$ & $152^{d}$ & 1130 & 55 \\
\hline$J_{\max }^{\prime}$ & 131 & 50 & 150 & 45 \\
\hline$K_{\max }^{\prime}$ & 22 & 14 & 32 & 14 \\
\hline $\mathrm{rms}$ & $0.072^{c}$ & $0.0009^{a, d}$ & $0.076^{c}$ & $0.0018^{a, d}$ \\
\hline$\sigma^{e}$ & \multicolumn{2}{|c|}{0.95} & \multicolumn{2}{|c|}{1.09} \\
\hline
\end{tabular}

ones at 1629.25 and $1632.07 \mathrm{~cm}^{-1}$ are assigned to $3 \mathrm{MP}-\mathrm{C} 1$ and 3MP-C3 conformers.

\section{B.3. Broad features in the $v_{36}$ and $v_{37}$ regions}

Interestingly, while the rotational structure was resolved in the $v_{18}$ band in the SPIRALES spectrum, no sign of such resolution 

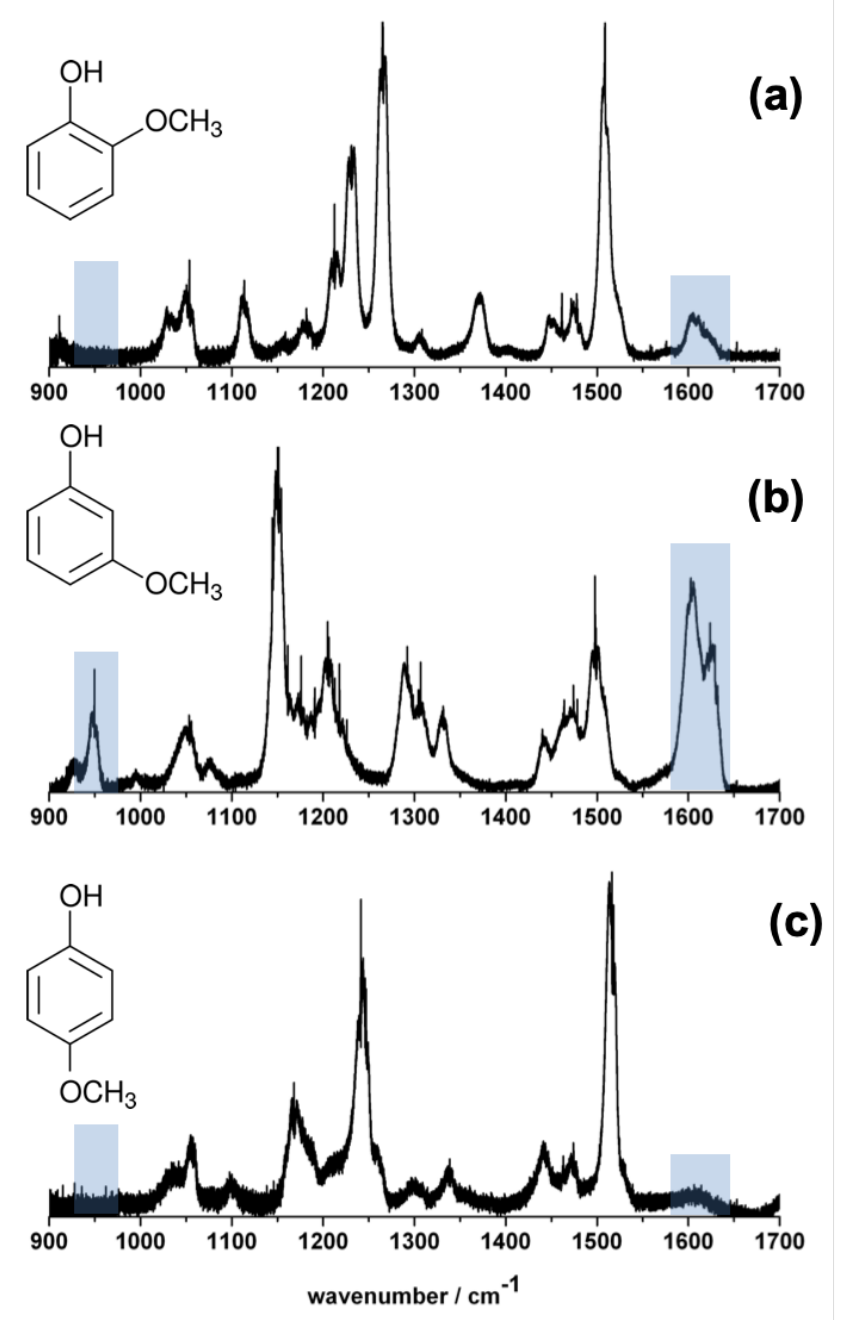

Fig. 4. Mid-IR Jet-AILES absorbance spectra of the 2MP (Fig.4a), 3MP (Fig.4b) and 4MP (Fig.4c) isomers measured in $5 \mathrm{slm}$ of Ar buffer gas. Blue areas indicates spectral regions reachable using the SPIRALES setup.

is visible for the $v_{36}$ and $v_{37}$ modes of $3 \mathrm{MP}$ under the same experimental conditions. Furthermore, the Q-branches of these bands appear broader than those of $v_{18}$. Further inspection of the Jet-AILES spectrum reveal that these two modes, corresponding to $\mathrm{C}-\mathrm{C}$ ring stretching, exhibit broader Q-branches than in-plane bending ones close in frequency $\left(\Delta v_{\mathrm{FWHM}}=0.35 \mathrm{~cm}^{-1}\right.$ versus $0.11 \mathrm{~cm}^{-1}$ ).

A simulation of the expected rovibrational SPIRALES spectra of $v_{36}$ and $v_{37}$, i.e. using the optimum modelization parameters defined for $v_{18}$ (a rotational temperature of $30 \mathrm{~K}$ and a FWHM of $0.004 \mathrm{~cm}^{-1}$ ) reveals that under the SPIRALES experimental conditions, a rotational resolution of these bands was expected. In this simulation, the experimental GS and scaled upper state constants were used, as the scaling has shown extremely reliable for the analysis of $v_{18}$. Additionally, the two bands at 1630.01 and $1632.49 \mathrm{~cm}^{-1}$, although unassigned, were simulated as well using constants from $3 \mathrm{MP}-\mathrm{C} 1$ in order to reproduce at best the strong rovibrational congestion in this
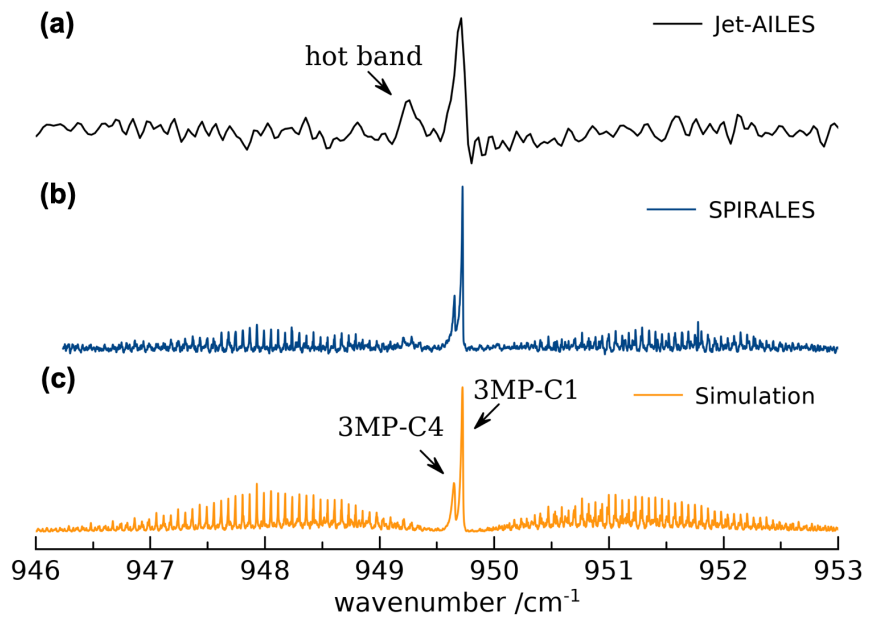

Fig. 5. Spectrum of the $v_{18}$ band of 3MP recorded using the Jet-AILES apparatus (Fig. 5a, in black) and the SPIRALES setup (Fig. 5b, in blue) and comparison with a $30 \mathrm{~K}$ simulation performed using PGOPHER at a $0.004 \mathrm{~cm}^{-1}$ FWHM (Fig. 5c, in orange) using rotational constants of $3 \mathrm{MP}-\mathrm{C} 1$ and $3 \mathrm{MP}-$ C4 conformers determined in this work (see Table 4). In the simulation, the relative abundances of both conformers are taken into account and the intensity of the $v_{18}$ band of 3MP-C4 is adjusted to 1.4 times that of $3 \mathrm{MP}-\mathrm{C} 1$ to reflect the experimental spectrum.

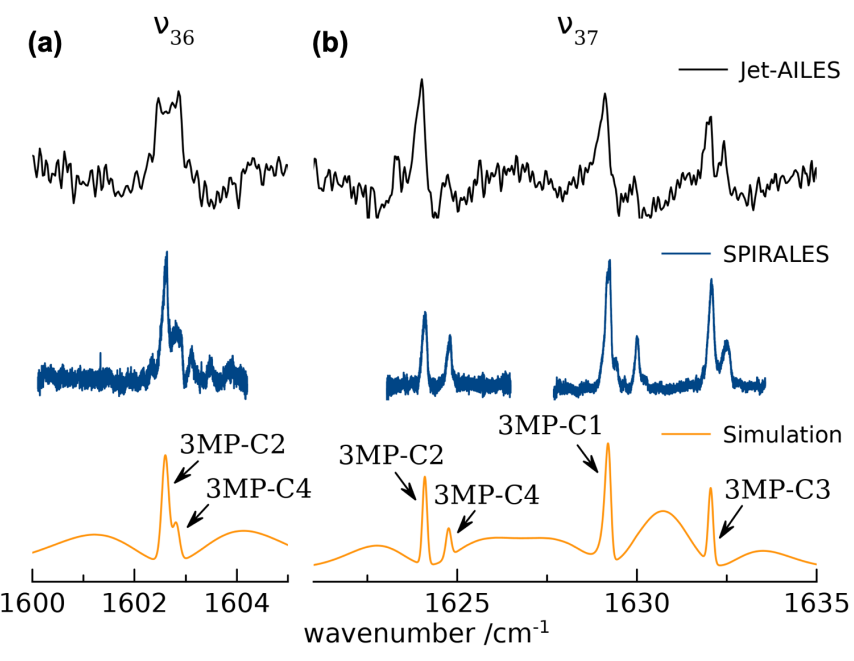

Fig. 6. Spectrum of the $v_{36}$ (Fig. 6a) and $v_{37}$ (Fig. 6b) bands of 3MP recorded using the Jet-AILES apparatus (top trace, in black) and the SPIRALES setup (middle trace, in blue) and comparison with a $30 \mathrm{~K}$ simulation performed using PGOPHER at a $0.15 \mathrm{~cm}^{-1}$ FWHM (bottom trace, in orange). GS rotation constants and upper state scaled constants from the DFT calculations were used in the simulation. The relative intensities of each conformer were obtained by taking into account the relative abundances of each conformer and the same band intensity was used for all bands of a given mode.

region . Despite a high density of vibrational bands, $\mathrm{P}$ and $\mathrm{R}$ rotational features remain clearly distinguishable in the simula- 
tion. Furthermore, the simulated Q-branches are narrower than what observed experimentally (see Fig. S3). It is thus likely that another effect is responsible for the spectral broadening, a plausible hypothesis being some vibrational perturbation although the responsible of which are not identified to date. Such perturbation could also explain the failure of anharmonic calculations to reproduce correctly the experimental spectrum, as already observed for the out-of-plane - $\mathrm{OH}$ bending mode (see section A) displaying large amplitude motions. It is worth noting that 3MP does not seem to be the only MP molecule affected by such effect, since in the case of the 2MP isomer no Q-branch of $v_{36,37} \mathrm{C}-\mathrm{C}$ ring stretching bands was detected using the JetAILES apparatus and these bands remained elusive using the SPIRALES setup. To help understand this effect, further investigation of related species should prove insightful, for instance the dihydroxybenzene $\left(\mathrm{C}_{6} \mathrm{H}_{5}(\mathrm{OH})_{2}\right)$ molecules in which the methoxy group of MP is replaced by an hydroxy group, a study that has been undertaken by some of us on the ortho isomer also called catechol[30].

\section{CONCLUSIONS}

The present study reports a low temperature rovibrational analysis of the three MP isomers using two complementary jet-cooled spectrometers: the Jet-AILES setup for low resolution FT broadband analysis in the fingerprint region $\left(100-1700 \mathrm{~cm}^{-1}\right)$ and the SPIRALES instrument using different EC-QCL sources allowing to measure at high resolution targeted mid-IR bands. With the Jet-AILES apparatus, narrow Q-branches were observed at low dilution using Ar as buffer gas. In the far-IR, Q-branches of the most intense out-of-plane-OH bending modes are unambiguously assigned for all the stable conformers. Moreover, guided by the anharmonic B3LYP/cc-pVTZ frequency calculations performed for each stable conformer, we propose for the three MP isomers corrected assignments and band centers values from narrow Q-branches measured in the FT-mid-IR Jet-AILES spectra. A first EC-QCL source covering the $930-990 \mathrm{~cm}^{-1}$ range has allowed to fully resolve the rotational structure of the $v_{18}$ in-plane ring bending bands of the 3MP-C1 and 3MP-C4 conformers. Two other EC-QCL sources covering the 1580-1690 $\mathrm{cm}^{-1}$ range have been used to probe the $\mathrm{C}-\mathrm{C}$ ring stretching $v_{36}$ and $v_{37}$ bands of $3 \mathrm{MP}$ and the associated stable conformers have been assigned. Compared to the $v_{18}$ analysis, it was not possible to proceed to the rovibrational analysis of the $v_{36}$ and $v_{37}$ bands which present broader Q-branches without visible Pand R-branches. The simulation of the expected rovibrational SPIRALES spectra suggests a possible vibrational perturbation responsible for the spectral broadening of the $v_{36}$ and $v_{37}$ bands. Nevertheless, the unambiguous conformer assignments obtained in the case of a rather large polyatomic molecule such as 3MP with four conformations significantly populated is a proof of the efficiency of high resolution QCL jet-cooled spectroscopy to analyze the conformational landscape of flexible molecules and to disentangle rovibrational signatures in a dense spectral region. The non-localized low-energy vibrational modes lying in the far-IR region also present a great potential for an efficient conformational discrimination [31] but, compared to the near-IR and UV domains, the available setups in this domain still lack of sensitivity. In a near future, new generation of QCL far-IR sources $[32,33]$ will offer real opportunities to probe and resolve at low temperature the lowest energy vibrational bands of individual conformers even for highly flexible molecules characterized by a rich conformational landscape. The conformational analysis is, for these molecules, the first step for a correct determination of the vibrational cross sections. In a second step, the additional difficulty to be overcome will lie in the analysis of the predominant hot bands at higher temperatures.

\section{SUPPLEMENTARY MATERIAL}

Three supplementary figures provide comparison of the measured SPIRALES spectra with Pgopher simulations of $v_{18}$ and $v_{36-37}$ based on the harmonic and anharmonic B3LYP/cc-pVTZ calculations. All computed fundamental harmonic and anharmonic frequencies, intensities and excited rotational constants are detailed in 7 Tables from $\mathrm{S} 1$ to $\mathrm{S} 7$, for the stable conformers 2MP-C1, 3MP-C1, 3MP-C2, 3MP-C3, 3MP-C4, 4MP-C1 and $4 \mathrm{MP}-\mathrm{C} 2$. The scaling of the rotational constants in $v_{18}=1$ is presented in Table S8. The line lists of the assigned rovibrational transitions of $v_{18}$ for 3MP-C1 and 3MP-C4 with SPIRALES are presented in Table S9 and S10.

\section{ACKNOWLEDGEMENTS}

The present work and the postdoctoral fellowship of A. Jabri take place in the Labex CaPPA (Chemical and Physical Properties of the Atmosphere) funded by the French National Research Agency (ANR) through the PIA (Programme d'Investissements d'Avenir) under contract ANR-11-LABX-005-01. The PhD of A. Roucou was supported by the Région Hauts-de-France and the French Direction Générale de l'Armement (DGA). The PhD of Y. Belkhodja was supported by the MESRI (Ministère de l'Enseignement Supérieur de la Recherche et de l'Innovation) within the doctoral school of Chimie Physique et Chimie Analytique de Paris Centre (ED 388). The authors are also grateful for the financial grant received from the Région Hauts-de-France, the Ministère de l'Enseignement Supérieur et de la Recherche (CPER Climibio), and the European Fund for Regional Economic Development. The authors are grateful to SOLEIL and the AILES staff for providing synchrotron beam under proposal 20170310. Additional acknowledgements go to the Centre de Ressources Informatiques de Lille 1 (CRI) where the GAUSSIAN16 calculations were performed.

\section{REFERENCES}

1. S. B. Hawthorne, D. J. Miller, R. M. Barkley, and M. S. Krieger. Environ. Sci. Technol., 22(10), 1191-1196 (1988).

2. C. D. Simpson, M. Paulsen, R. L. Dills, L.-J. S. Liu, and D. A. Kalman. Environ. Sci. Technol., 39(2), 631-637 (2005).

3. C. Liu, J. Liu, Y. Liu, T. Chen, and H. He. Atmos. Environ., 207, 30-37 (2019).

4. A. Lauraguais, C. Coeur-Tourneur, A. Cassez, K. Deboudt, M. Fourmentin, and M. Choël. Atmos. Environ., 86, 155-163 (2014).

5. C. Clerbaux, A. Boynard, L. Clarisse, M. George, J. Hadji-Lazaro, H. Herbin, D. Hurtmans, M. Pommier, A. Razavi, S. Turquety, C. Wespes, and P. F. Coheur. Atmos. Chem. Phys., 9(16), 6041-6054 (2009). doi: $\{10.5194 /$ acp-9-6041-2009\}. 
6. P. F. Coheur, H. Herbin, C. Clerbaux, D. Hurtmans, C. Wespes, M. Carleer, S. Turquety, C. P. Rinsland, J. Remedios, D. Hauglustaine, C. D. Boone, and P. F. Bernath. Atmos. Chem. Phys., 7(20), 5437-5446 (2007). doi: $\{10.5194 / \mathrm{acp}-7-5437-2007\}$.

7. A. Cuisset, C. Coeur, G. Mouret, W. Ahmad, A. Tomas, and O. Pirali. J. Quant. Spectrosc. Radiat. Transfer, 179, 51-58 (2016).

8. A. Roucou, D. Fontanari, G. Dhont, A. Jabri, C. Bray, F. Hindle, G. Mouret, R. Bocquet, and A. Cuisset. ChemPhysChem, 19(13), 1572-1578 (2018).

9. A. Jabri, D. Fontanari, A. Roucou, C. Bray, F. Hindle, G. Dhont, G. Mouret, R. Bocquet, and A. Cuisset. J. Chem. Phys., 150(10) (2019). doi: $\{10.1063 / 1.5089426\}$.

10. E. L. Sibert, III, D. P. Tabor, N. M. Kidwell, J. C. Dean, and T. S. Zwier. J. Phys. Chem. A, 118(47), 11272-11281 (2014).

11. J. A. Ruiz-Santoyo, M. Rodríguez-Matus, J. L. Cabellos, J. T. Yi, D. W. Pratt, M. Schmitt, G. Merino, and L. Álvarez-Valtierra. J. Chem. Phys., 143(9), 094301 (2015).

12. M. Wilke, M. Schneider, J. Wilke, J. A. Ruiz-Santoyo, J. J. CamposAmador, M. E. González-Medina, L. Álvarez-Valtierra, and M. Schmitt. J. Mol. Struct., 1140, 59-66 (2017).

13. S. Kim, P. A. Thiessen, E. E. Bolton, J. Chen, G. Fu, A. Gindulyte, L. Han, J. He, S. He, B. A. Shoemaker, J. Wang, B. Yu, J. Zhang, and S. H. Bryant. Nucleic Acids Res., 44(D1), D1202-D1213 (2016). doi: $\{10.1093 /$ nar/gkv951\}.

14. M. Cirtog, P. Asselin, P. Soulard, B. Tremblay, B. Madebene, and M. E. Alikhani. J. Phys. Chem. A, 115(12), 2523-2532 (2011). doi: $\{10.1021 / j p 111507 z\}$.

15. P. Asselin, B. Madebene, P. Soulard, R. Georges, M. Goubet, T. R. Huet, O. Pirali, and A. Zehnacker-Rentien. J. Chem. Phys., 145(22) (2016). doi: $\{10.1063 / 1.4972016\}$.

16. P. Asselin, A. Potapov, A. C. Turner, V. Boudon, L. Bruel, M.-A. Gaveau, and M. Mons. Phys. Chem. Chem. Phys., 19(26), 17224-17232 (2017). doi: $\{10.1039 / \mathrm{c} 7 \mathrm{cp} 02529 \mathrm{~g}\}$.

17. A. Jabri, Y. Belkhodja, Y. Berger, I. Kleiner, and P. Asselin. J. Mol. Spectrosc., 349, 32-36 (2018). doi : \{10.1016/ j. jms. 2018.03. $012\}$.

18. L. S. Rothman, I. E. Gordon, Y. Babikov, A. Barbe, D. C. Benner, P. F. Bernath, M. Birk, L. Bizzocchi, V. Boudon, L. Brown, A. Campargue, K. Chance, E. Cohen, L. H. Coudert, V. M. Devi, B. Drouin, A. Fayt, J.-M. Flaud, R. Gamache, J. J. Harrison, J.-M. Hartmann, C. Hill, J. T. Hodges, D. Jacquemart, A. Jolly, J. Lamouroux, R. L. Roy, G. Li, D. Long, O. Lyulin, C. J. Mackie, S. T. Massie, S. Mikhailenko, H. Mueller, O. Naumenko, A. V. Nikitin, J. Orphal, V. Perevalov, A. Perrin, E. R. Polovtseva, C. Richard, M. A. H. Smith, E. Starikova, K. Sung, S. Tashkun, J. Tennyson, G. C. Toon, r. Tyuterev, and G. Wagner. J. Quant. Spectrosc. Radiat. Transfer, 130(SI), 4-50 (2013).

19. M. D. Brookes, C. Xia, J. Tang, J. A. Anstey, B. G. Fulsom, K.-X. A. Yong, J. M. King, and A. McKellar. Spectrochimica Acta Part A: Molecular and Biomolecular Spectroscopy, 60(14), 3235 - 3242 (2004). doi: $10.1016 / j$.saa.2003.11.041.

20. X. Liu, Y. Xu, W. Su, Z.and Tam, and L. I. Appl. Phys. B: Lasers Opt, 102, 629-639 (2011). doi:10.1007/s00340-010-4147-y.

21. M. Frisch, G. Trucks, H. Schlegel, G. Scuseria, M. Robb, J. Cheeseman, G. Scalmani, V. Barone, G. Petersson, H. Nakatsuji, et al. Gaussian 16, revision A.03. Gaussian Inc., Wallingford CT (2016).

22. R. A. Kendall, T. H. Dunning Jr, and R. J. Harrison. J. Chem. Phys., 96(9), 6796-6806 (1992).

23. L. Cesari, L. Canabady-Rochelle, and F. Mutelet. Struct. Chem., 29(1), 179-194 (2018).

24. V. Barone, M. Biczysko, and J. Bloino. Phys. Chem. Chem. Phys., 16, 1759-1787 (2014). doi: $\{10.1039 /$ c3cp53413h $\}$.

25. T. Häber, U. Schmitt, and M. A. Suhm. Phys. Chem. Chem. Phys., 1, 5573-5582 (1999). doi:10.1039/A907264K.

26. M. Goubet, P. Soulard, O. Pirali, P. Asselin, F. Réal, S. Gruet, T. R. Huet, P. Roy, and R. Georges. Phys. Chem. Chem. Phys., 17, 7477-7488 (2015). doi:10.1039/C4CP05684A.

27. C. Western. J. Quant. Spectrosc. Radiat. Transfer, 186, 221-242 (2016).
28. W. Lodyga, M. Kreglewski, P. Pracna, and S. Urban. J. Mol. Spectrosc., 243, 182-188 (2007).

29. H. M. Pickett. J. Mol. Spectrosc., 148, 371-377 (1991).

30. M. Gerhards, W. Perl, S. Schumm, U. Henrichs, C. Jacoby, and K. Kleinermanns. J. Chem. Phys., 104(23), 9362-9375 (1996).

31. A. Cuisset, G. Mouret, O. Pirali, P. Roy, F. Cazier, H. Nouali, and J. Demaison. J. Phys. Chem. B, 112(39), 12516-12525 (2008). doi: $\{10.1021 / j p 804665 \mathrm{~h}\}$.

32. M. Bahriz, G. Lollia, A. N. Baranov, and R. Teissier. Opt. Express, 23(2), 1523-1528 (2015).

33. K. Ohtani, M. Beck, M. J. Suess, J. Faist, A. M. Andrews, T. Zederbauer, H. Detz, W. Schrenk, and G. Strasser. ACS Photonics, 3(12), 2280$2284(2016)$ 